\title{
Sampling follicular fluid without altering follicular status in cattle: oestradiol concentrations early in a follicular wave
}

\author{
O. J. Ginther ${ }^{1}$, K. Kot ${ }^{1}$, L. J. Kulick ${ }^{1}$ and M. C. Wiltbank ${ }^{2}$ \\ ${ }^{1}$ Department of Animal Health and Biomedical Sciences and ${ }^{2}$ Department of Dairy Science, University of \\ Wisconsin-Madison, Madison, WI 53706 USA
}

\begin{abstract}
A transvaginal, ultrasound-guided in situ technique was developed for sampling follicular fluid from $6.0-12.5 \mathrm{~mm}$ follicles in cattle, with minimal interference with the subsequent development of the sampled follicle. Each follicle was sampled only once and the status of the follicle (future dominant or subordinate) was determined retrospectively. A sample $(20 \mu \mathrm{l})$ was successfully obtained from $77 \%$ of 132 targeted follicles. Reasons for considering an attempt unsuccessful were as follows: (1) ovaries difficult to manipulate in two heifers (eight follicles), (2) samples contaminated with blood (II samples), and (3) follicles sampled but the antrum subsequently developed an apparent blood clot (11 follicles). Only the 102 successful collections were used in the statistical analyses for evaluating oestradiol concentrations in the follicular fluid and the follicle growth profiles before and after sampling. The follicles were sampled once on days 1, 2, 3, or 4 after the emerging dominant follicle was $4 \mathrm{~mm}$ in diameter. On day 1 , there were no differences in the oestradiol concentrations among follicles that later became the dominant follicle, largest subordinate follicle, or smaller subordinate follicles (means for diameters, 6.7-6.9 mm; means for oestradiol, $30-42 \mathrm{ng} \mathrm{ml}^{-1}$ ). The mean diameter of the dominant follicle increased linearly over the 4 days. Concentrations of oestradiol in the dominant follicle increased curvilinearly, resulting from a slower increase between days 1 (mean, $42 \mathrm{ng} \mathrm{ml}^{-1}$ ) and 2 (110 $\mathrm{ng} \mathrm{ml}^{-1}$ ) than between days 2 and $3\left(313 \mathrm{ng} \mathrm{ml}^{-1}\right.$ ) and 3 and $4\left(554 \mathrm{ng} \mathrm{ml}^{-1}\right)$. Neither mean diameter nor mean oestradiol concentration of the largest subordinate follicle increased after day 2. Data were available from 19 follicular waves in which both the dominant and largest subordinate follicles were sampled on the same day. Oestradiol concentrations were not higher in the dominant follicle than in the largest subordinate follicle until the day after the two follicles began to deviate in growth rates (mean day of deviation, $2.5 \pm 0.2$ days after emergence). These observations indicate that the future dominant follicle cannot be identified reliably by either its diameter or oestradiol production before the deviation in growth rates between the two largest follicles.
\end{abstract}

\section{Introduction}

The development of follicular waves in cattle involves partitioning into a dominant follicle that reaches $10-16 \mathrm{~mm}$ and subordinate follicles that regress after reaching $6-9 \mathrm{~mm}$ in diameter (for review see Ginther et al., 1989). The future dominant follicle and the largest subordinate follicle do not begin to deviate in growth rates until 2-3 days after the future dominant follicle emerges at $4 \mathrm{~mm}$ (Ginther et al., 1996). On average, a surge in circulating concentrations of FSH reaches a peak on the day of emergence of the dominant follicle and a nadir on the day when the growth rates between the two largest follicles begin to deviate (Ginther et al., 1996). The mechanism for regulating the initial declining portion of the FSH surge is unknown. Apparently, the final suppression of the surge is a component of the deviation mechanism, and

Received I July 1996 maintenance of the basal FSH concentrations is a function of the growing dominant follicle after deviation; the FSHdependent subordinate follicles cease to grow because of low FSH concentrations, whereas the selected dominant follicle continues to grow by a shift in primary gonadotrophin dependency from FSH to LH (for review see Ginther et al., 1996).

The identities of follicular inhibitory substances responsible for the final and continued depression of FSH and potential follicular facilitatory substances involved in the change in gonadotrophin dependency to LH have not been clarified. Oestradiol could be involved in the deviation mechanism because the dominant follicle produces and releases oestradiol, apparently at the approximate time of deviation and throughout its growing phase (Ginther et al., 1996). Deviation begins when the future dominant follicle is $8.5 \mathrm{~mm}$ in diameter (Ginther et al., 1996), and follicular-fluid oestradiol concentrations in the largest follicle are high when its mean diameter 
is 8-9 mm (Martin et al., 1991; Guilbault et al., 1993; Xu ef al., 1995; Bodensteiner et al., 1996a). However, the temporal and functional relationships between deviation and concentrations of oestradiol in the follicular fluid of the two largest follicles are unknown. A research obstacle is that the future dominant and subordinate follicles cannot be distinguished reliably if follicular fluid is obtained terminally before the largest follicle is $>9 \mathrm{~mm}$ in diameter or the difference in diameter between the two largest follicles is $>3 \mathrm{~mm}$ (Bodensteiner ot al., 1996b).

The purpose of this experiment was to develop a method for sampling the follicular fluid of individual follicles in situ before deviation without altering their future status as dominant and subordinate follicles. The methodology was tested by assaying oestradiol concentrations in follicular fluid collected from follicles ranging from $6 \mathrm{~mm}$ to $12 \mathrm{~mm}$ in diameter.

\section{Materials and Methods}

Holstein heifers, 1.5-2.0 years of age and weighing 490$770 \mathrm{~kg}$, were used during March and April. Daily transrectal ultrasound examinations of the ovaries were done by a single operator to detect ovulation and to monitor or track from day to day individually identified follicles of the first postovulatory follicular wave. The monitoring scanner had a $7.5 \mathrm{MHz}$ lineararray transducer. The day of wave emergence was defined as the last day the retrospectively identified dominant follicle was $4 \mathrm{~mm}$ in diameter. A $5.0 \mathrm{MHz}$ convex-array transducer was used for the transvaginal sampling of follicular fluid, using a system that has been described for intrafollicular injection into dominant follicles (Kot et al., 1995). The transducer was mounted in a plastic handle containing a needle guide $47 \mathrm{~cm}$ in length. A double-channel system was used for the sampling and consisted of a 20-gauge outer needle (outer diameter, $0.91 \mathrm{~mm}$; inner diameter, $0.55 \mathrm{~mm}$; length, $53 \mathrm{~cm}$ ) and a 25 -gauge inner needle (outer diameter, $0.52 \mathrm{~mm}$; inner diameter, $0.24 \mathrm{~mm}$; length, $57 \mathrm{~cm}$ ). The inner needle was filled with physiological saline. The perineal area was scrubbed and caudal epidural anaesthesia was induced. The transducer face was applied to the wall of the vaginal fornix. The ovary containing the follicle for sampling was positioned transrectally against the vaginal wall over the transducer face, so that the targeted follicle was transected by the built-in line on the ultrasound monitor representing the projected needle path. The needle path to the follicle was positioned so that it transected the ovarian stroma but not other detectable follicles or luteal tissue. The inner needle was inserted into the outer needle until the tip was approximately $1 \mathrm{~cm}$ before the tip of the outer needle, and the needles were then inserted into the needle guide of the transvaginal probe. When the ovary and targeted follicle were in position and tight against the vaginal wall, the needles were advanced by a second operator until the image of the tip of the outer needle became visible on the scanner screen, indicating that the vaginal wall and peritoneum were penetrated. The inner needle was then advanced until the image of the inner needle tip was centered within the targeted follicle. Aspiration of follicular fluid was done by the second operator with a $100 \mu \mathrm{l}$ syringe preset to the desired sample volume $(20 \mu \mathrm{l})$ during continuous observation of the needle tip. The needles and probe were withdrawn immediately after sampling to avoid exerting continued pressure on the newly sampled follicle. The sample was inserted into tapered microtubes and stored at $-20^{\circ} \mathrm{C}$.

The follicles were individually identified and measured in eight heifers without sampling (controls). Follicular-fluid sampling was attempted 1-4 days after wave emergence for 132 follicles $(6.0-12.5 \mathrm{~mm})$ in 22 heifers and 43 waves. Individual follicles were sampled only once, but in ten waves separate follicles were sampled on 2 days. The follicles were retrospectively classified into three types as follows: dominant follicle, largest subordinate follicle, and smaller subordinate follicles (Ginther et al., 1989). The sample was inspected and categorized as clear, tinged with blood (pink, translucent), or extensively contaminated with blood (red, opaque). The sampled follicles were monitored daily by ultrasound until 12 days after wave emergence. The post-sampling condition of the follicle as imaged by ultrasound was recorded as normal (anechoic follicular fluid) or containing echogenic matter in the follicular fluid.

The diameters of the dominant follicles from the day of emergence to 8 days later were compared between the control group and four groups with the dominant follicle sampled 1, 2, 3 , or 4 days after emergence, using day-by-group factorial analyses of variance for sequential data. In addition, growth rate was used as a common endpoint to permit combining of sampled follicles; growth rate was analysed for the day before, the day of, and the 2 days after sampling. The maximum diameter attained by the dominant follicle when sampled at different diameters was compared with the maximum diameter of control follicles by analysis of variance.

Concentrations of oestradiol were evaluated with specific ELISA as previously described by Rasmussen et al. (1996) and modified for direct use with follicular fluid (Bodensteiner et al., 1996b). Briefly, follicular fluid samples were diluted 1:100 in assay buffer and analysed directly with the ELISA. The standard curve contained oestradiol concentrations from 31 to $2000 \mathrm{pg} \mathrm{ml}^{-1}$ in a 1:100 dilution of charcoal-treated follicular fluid. The intra-assay and interassay coefficients of variation were $8.0 \%$ and $12.6 \%$, respectively. The minimum sensitivity ( 3 sDs from total binding) was equivalent to a concentration of $1.03 \mathrm{ng} \mathrm{ml}^{-1}$ in unknown samples.

The diameter of follicles and concentrations of oestradiol in the follicular fluid were examined with a day (days 1, 2, and 3 after emergence) by follicle (dominant, largest subordinate, and smaller subordinates) factorial analysis of variance. Significant interactions were further examined by Duncan's multiple range tests for differences among means within each day. For these analyses, if more than one follicle of a given type (two dominant follicles or two or more smaller subordinate follicles) were sampled on a given day in a wave, the daily mean for the wave was used as a single value. The two endpoints for the dominant follicle (diameter and oestradiol concentration) were also examined by regression analysis with the endpoint as the dependent variable and day as the independent variable.

The day at the beginning of deviation in growth rates of the dominant and largest subordinate follicles was identified for 19 follicular waves in which a sample of follicular fluid was available from both follicles on the same day. Day of deviation was chosen as described by Ginther et al. (1996) on the basis of 


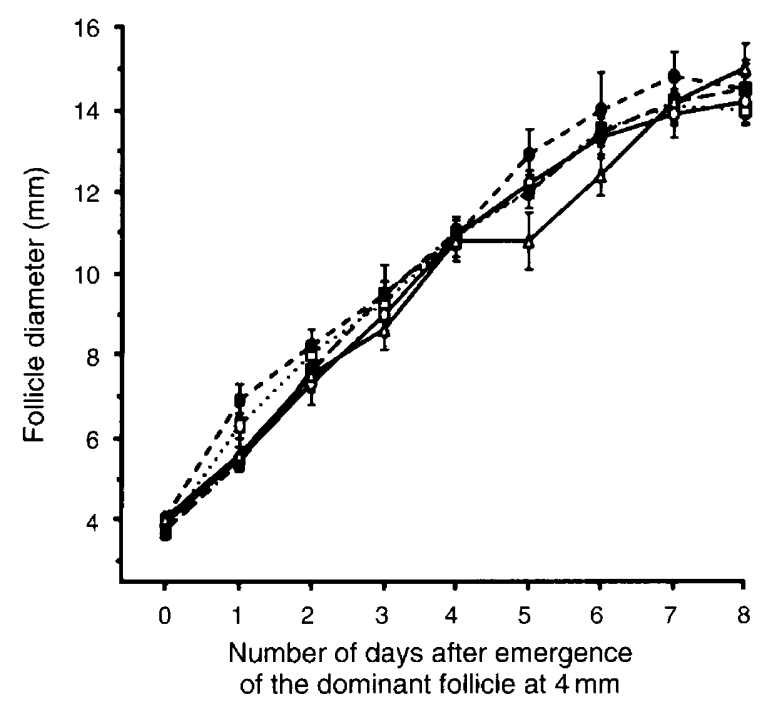

Fig. 1. Diameter (mean \pm SEM) of dominant follicle in control follicular waves $(O ; n=8)$ and in waves in which a follicular fluid sample was taken from the dominant follicle on day $I(n=4)$, day 2 $(\square ; n=14)$, day $3(\mathbb{\square} ; n=15)$, or day $4(\triangle ; n=8)$. A main effect of day $(P<0.0001)$ but no significant effect of group or a group-by-day interaction was observed.

the greatest difference in growth rates between the two follicles before or on the day the subordinate follicle reached maximum diameter. Oestradiol concentrations were studied by analysis of variance, as described above, and a significant interaction was followed by paired $t$ tests between the two follicles for each day, from $I$ day before to 2 days after the beginning of deviation.

\section{Results}

Collection of a sample of follicular fluid was successful for 113 follicles, including seven samples tinged with blood but excluding samples for eight follicles in two heifers in which ovarian manipulation was difficult and 11 samples that were extensively contaminated with blood (sampling success rate: 113 of 132; that is, $86 \%$ ). The 7 of $113(6 \%)$ samples tinged with blood were included because the concentrations of oestradiol were not significantly different from the 106 samples that were scored as clear. Eleven of $124(9 \%)$ samples with extensive blood contamination were excluded because the oestradiol concentrations were low $\left(<5 \mathrm{ng} \mathrm{ml}^{-1}\right.$ in six samples). Data were not used for 11 follicles because of post-sampling formation of an echogenic mass comprising $20-80 \%$ of the antrum. In summary, both a satisfactory sample and data from post-sampling follicle monitoring were obtained from 102 of $132(77 \%)$ targeted follicles.

Comparison of the growth profile for the dominant follicle showed a day effect (days $0-8 ; P<0.0001$ ) but no group effect (controls and sampling on days 1-4) or an interaction (Fig. 1). When sampled groups were combined, the growth rate $\left(\mathrm{mm}\right.$ day $\left.^{-1}\right) 0$ to $I$ days after sampling $(1.1 \pm 0.2)$ was less $(P<0.004)$ than for the day before the day of sampling $(2.0 \pm 0.2)$, and the mean growth rate between the day of sampling and the following day tended to be smaller $(P<0.1)$
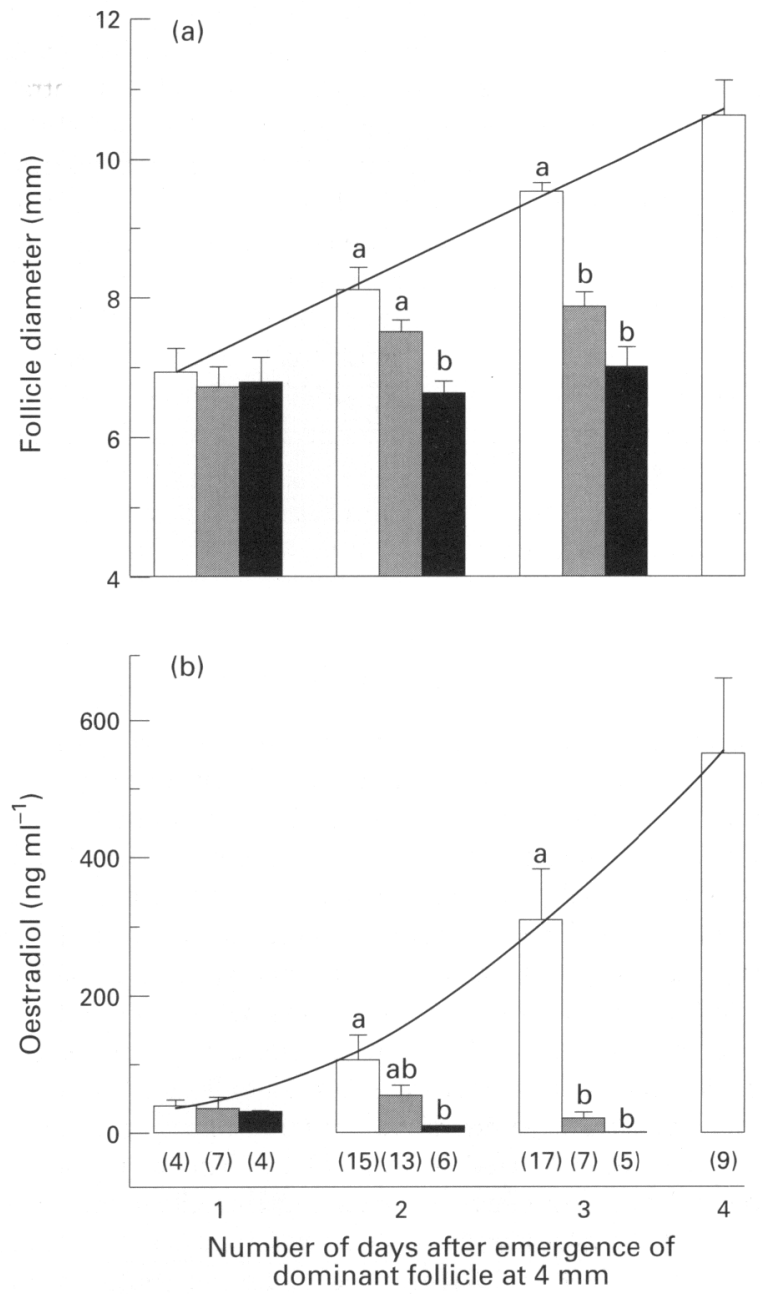

Fig. 2. (a) Diameters and (b) oestradiol concentrations (mean $\pm S E M$ ) of dominant follicles $(\square)$, largest subordinate follicles $(\square)$ and smaller subordinate follicles ( $\square$ ). The linear regression line (a) and the curvilinear regression line (b) that best characterized the changing diameters and oestradiol concentrations of the dominant follicles are shown. The numbers of observations for both panels are shown in parentheses on the bottom of the lower panel. Within each day and endpoint, means with different letters are significantly different $(P<0.05)$.

in the sampled follicles $(1.1 \pm 0.2)$ than in control follicles $(1.6 \pm 0.1)$. The maximum diameter of the dominant follicle was not significantly different among the control group $(16.4 \pm 0.5 \mathrm{~mm}$ ) and sampled groups (means of $14.8 \pm 0.7$ to $16.1 \pm 0.4 \mathrm{~mm}$ for the follicles sampled at $6,7,8,9,10$ or $11 \mathrm{~mm})$. When all sampled groups were combined, the difference between the control group ( $16.4 \pm 0.5 \mathrm{~mm})$ and sampled group $(15.4 \pm 0.6 \mathrm{~mm})$ tended $(P<0.1)$ to be different.

The mean diameters of the three follicle types for 1,2 , and 3 days after wave emergence and for the dominant follicle at 4 days are shown (Fig. 2). The dominant follicle showed a linear increase in diameter over the 4 days. The corresponding oestradiol concentrations in the follicular fluid are also shown (Fig. 2b). The oestradiol concentrations of the dominant follicle showed an increase characterized by a second-order polynomial regression. 

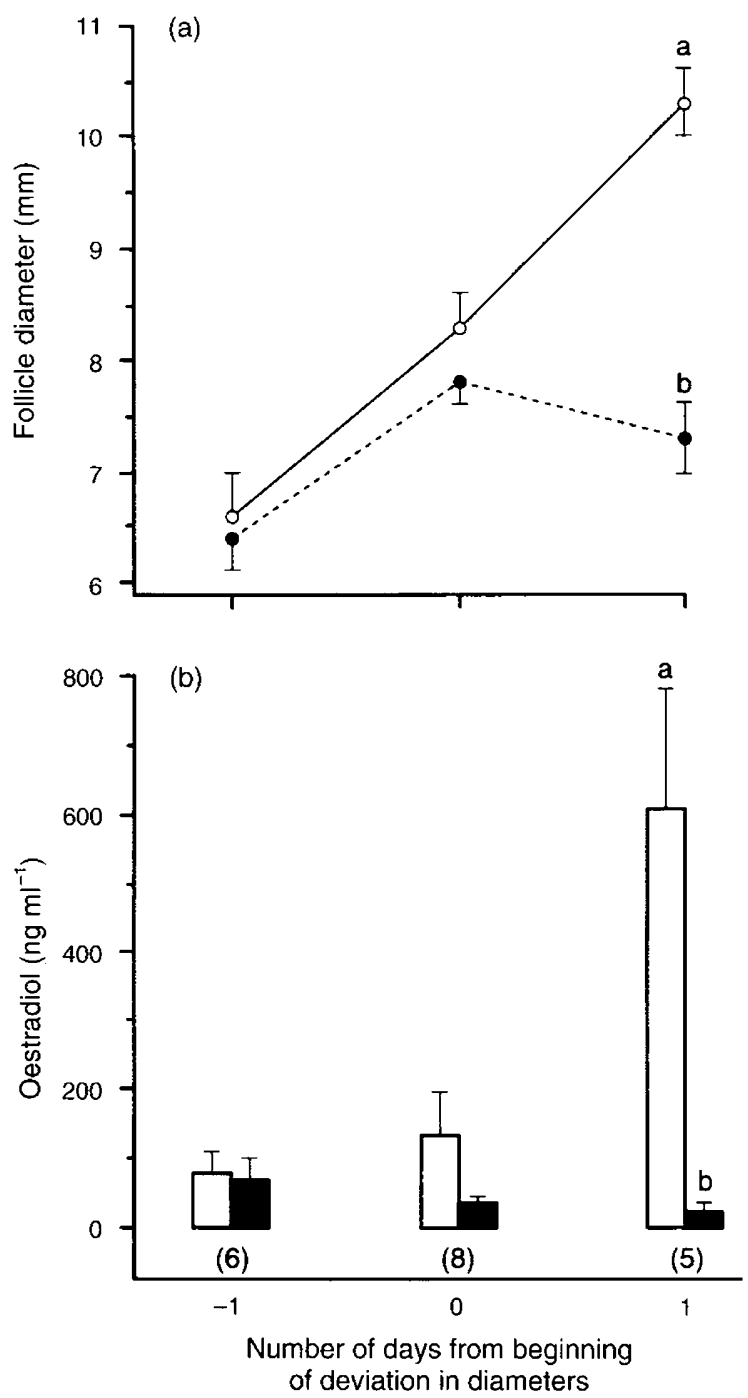

Fig. 3. (a) Diameters (mean \pm SEM) of dominant follicle $(O)$ and largest subordinate follicle ( ) for 19 follicular waves before and after the two follicles began to deviate in diameter, and (b) oestradiol concentrations in follicular fluid of dominant follicle $(\square)$ and largest subordinate follicle ( $\boldsymbol{\square}$ ). The number of waves with sampled follicles is shown in parentheses for each day. Means for each end point were significantly different $(P<0.05)$ only on the day after the beginning of deviation as indicated by different letters.

On average, deviation occurred $2.5 \pm 0.2$ days after wave emergence. In the 19 waves displaying deviation data, the day-by-follicle type interaction was significant for concentrations of oestradiol. Oestradiol concentrations were not different between the dominant follicles and largest subordinate follicles on the day before and the day at the beginning of deviation, but were greater $(P<0.05)$ for the dominant follicles than for the largest subordinate follicles on the day after the beginning of deviation (Fig. 3).

\section{Discussion}

The ultrasound-guided transvaginal technique was effective for sampling follicular fluid for follicles $6-12 \mathrm{~mm}$ in diameter in heifers that were acclimatized to the chutes and transrectal examinations. No attempt was made to sample smaller follicles or to sample an individual follicle more than once. Mature follicles (dominant follicles at 6 days after ovulation) have been successfully penetrated for local hCG induction of ovulation, using the same equipment (Kot et al., 1995). In the present study, the volume of sampled follicular fluid $(20 \mu \mathrm{l})$ was approximately $18 \%, 7 \%$, and $4 \%$ of the fluid volume of a spherical follicle with an antral diameter of 6,8 , and $10 \mathrm{~mm}$, respectively. The results of a preliminary trial indicated that aspiration of a consistent volume required an inner needle that was filled with fluid. Five attempts to withdraw $20 \mu \mathrm{l}$ of follicular fluid from follicles with a diameter of $6-15 \mathrm{~mm}$ when the needle was filled with air yielded volumes of $0,5,8,10$ and $20 \mu \mathrm{l}$. After completion of the study, it was found that the $10 \mu \mathrm{l}$ at the needle tip of an aspirated volume of $20 \mu \mathrm{l}$ contained $3-11 \%$ more oestradiol than the remaining $10 \mu \mathrm{l}$, indicating some mixing had occurred between the follicular fluid and the saline solution in the needle. Trials are needed to determine whether such error can be reduced by using only a portion of the aspirated follicular fluid nearest to the needle tip or by the presence of a small air pocket between the saline solution and follicular fluid.

The mean day of wave emergence for the 43 waves was $1.1 \pm 0.1$ days before ovulation. Most $(63 \%)$ waves emerged on the day before ovulation. An unusual occurrence was the emergence of a wave 3 days after ovulation in a heifer that had one wave for the oestrous cycle; this was the only wave that emerged after ovulation. Wave emergence at a mean of I.I days before ovulation in this study corresponds to reports of emergence at means of 0.2 and 0.5 days before ovulation in another study by Ginther et al. (1989). The difference between this study and other reported studies is attributable to defining emergence as occurring when the dominant follicle was $4 \mathrm{~mm}$ (the day before the follicle grew to $5 \mathrm{~mm}$ ), whereas in the previous studies emergence was defined at 4 or $5 \mathrm{~mm}$.

Two of 22 heifers were unsuitable for the transvaginal follicular-fluid sampling procedure because of problems associated with ovarian manipulation. The extent of fluid loss from the volume removed as well as possible leakage following needle penetration was evaluated 1 day after sampling in the dominant follicles because a reduction in follicle diameter could be confused with normal regression in the other follicles. There was a tendency for a mean reduction in rate of growth after sampling and maximal attained diameter of the sampled dominant follicle. The effect of sampling on maximal diameter was slight (16.4 versus $15.4 \mathrm{~mm}$ ). However, severe leakage appeared to have occurred in one dominant follicle as indicated by a reduction in diameter from $11.4 \mathrm{~mm}$ to $7.5 \mathrm{~mm}(34 \%$ decrease) on the day after sampling. The follicle returned to approximately its original diameter the next day and thereafter continued to grow. Procedures that may have reduced leakage included the use of a fine-entry needle (25-gauge), directing the needle path through the stroma, and immediate needle withdrawal without subsequent ovarian manipulation.

Extensive blood contamination was present in $9 \%$ of the samples and these were thus considered unsuccessful. The frequency of blood-contaminated samples decreased as the experiment progressed. For example, five of the first $16 \%$ of samples collected were contaminated compared with six of the 
last $84 \%$. Better maintenance of the needle tip in the centre of the follicle and better coordination between the two operators may account for some of the improved success with increased experience.

The nearly normal growth profile of sampled dominant follicles indicates that interference of sampling with subsequent follicle function was minimal. In addition, the mean day of emergence of the second wave after sampling (8.5 \pm 0.2 days after emergence of the first wave) was not significantly different from the day of emergence in control oestrous cycles ( $9.2 \pm 0.7$ days). In this regard, destruction of the dominant follicle early in the first wave caused early emergence of the second wave (Ko et al., 1991), suggesting that reduced function of the dominant follicle in the present study would have hastened emergence of the next wave. There were only six waves in which only the dominant follicle was sampled. The follicle was sampled when it was $8.9-10.5 \mathrm{~mm}$ and did not lose its dominant status in any of the six waves. Although these observations suggest normal function of dominant follicles after sampling, more study will be needed for critical evaluation.

In some follicles, a white streak in the follicular wall and occasionally a white speck on the inner wall were imaged. These streaks probably represented the needle path. In $11 \%$ of sampled follicles, a white echogenic mass equivalent to $20-80 \%$ of the antral volume formed $1-3$ days after sampling. These masses probably represented a clot of blood, since they had the echotexture of blood experimentally injected into follicles (Ginther, 1995). It is not known whether these apparent clots altered follicular function or diameter but, as a precaution, the samples and follicles were not used in the analyses.

The diameter (approximately $8 \mathrm{~mm}$ ) of the dominant follicle and the concentration of oestradiol in the follicular fluid (approximately $100 \mathrm{ng} \mathrm{ml}^{-1}$ ) of the dominant follicle 2 days after wave emergence in this study were similar to those reported by Martin et al. (1991) in which the follicular fluid was obtained from apparent dominant follicles of removed ovaries 3 days after oestrus. The increases in oestradiol concentrations in the follicular fluid of the dominant follicle over days 2-4 after emergence of the follicular wave in the present study are consistent with oestradiol increases in the follicular fluid of growing follicles in ovaries removed 1-6 days after oestrus (Sunderland et al., 1996), in venous blood during the early luteal phase (Kaneko et al., 1991), and from cannulated ovarian veins $72-168 \mathrm{~h}$ after the LH surge (Ireland et al., 1984).

Hypotheses on the role of oestradiol in early development of a follicular wave and in the partitioning into a dominant follicle and subordinate follicles were not under test in this study. However, several observations were made. On the day after emergence of the dominant follicle there were no differences in follicular fluid oestradiol concentrations among follicles (smallest accepted diameter, $6 \mathrm{~mm}$ ) that later became dominant, largest subordinate, or smaller subordinates. The diameter of the dominant follicle increased linearly over the first 4 days after emergence. Oestradiol concentrations increased curvilinearly, resulting from a more rapid increase after day 2 than between days 1 and 2 . Thus, the increased concentrations of oestradiol in the dominant follicle began between days 2 and 3, which corresponds to the mean day at the beginning of deviation in growth rates between the two largest follicles in this study (2.5 days after emergence) and a reported study (2.8 days; Ginther et al., 1996). Neither the diameter nor oestradiol concentration of the largest subordinate follicle increased after day 2. Data were available from 19 waves for studying the oestradiol concentrations in the dominant and largest subordinate follicles before and after deviation. Oestradiol concentrations did not differ between the two follicles until the day after the beginning of deviation in diameters; that is, the future dominant follicle would not have been identifiable by either its diameter or oestradiol concentration until deviation occurred.

The oestradiol concentration was below assay sensitivity ( $1.0 \mathrm{ng} \mathrm{ml}^{-1}$ ) for $22(22 \%$ ) of the follicular-fluid samples used in the analyses. The proportion of samples with no detectable oestradiol was greatest $(P<0.05)$ for the smaller subordinate follicles 3 days after wave emergence (six of seven follicles) than for any of the other eight groups (three follicle types on 3 days). Six samples with no detectable oestradiol were obtained from dominant follicles $2-4$ days after wave emergence when the follicles were $7.5-12.5 \mathrm{~mm}$ in diameter. The six samples were re-assayed and the undetectable concentrations were confirmed. The maximal attained diameter of dominant and largest subordinate follicles and day of emergence of the second follicular wave in association with these six follicles were not significantly different from these endpoints in follicular waves with detected concentrations of oestradiol in the dominant follicle. Thus, the reason and consequences of the lack of detected oestradiol in these samples are not known.

In conclusion, the results indicated that collection of follicular fluid in situ can be done in follicles as small as $6 \mathrm{~mm}$ in diameter. The procedure apparently had minimal interference with subsequent development of the follicles. The potential of the technique was demonstrated in the studies of the interrelationships between follicular-fluid oestradiol and follicular dynamics.

This research was supported by the College of Agricultural and Life Sciences, University of Wisconsin, and USDA grant No. 9401480. The authors thank $\mathrm{C}$. Bartol for manuscript preparation.

\section{References}

Bodensteiner KJ, Kot K, Wiltbank MC and Ginther OJ (1996a) Synchronization of emergence of follicular waves in cattle Theriogenology 45 1115-1128

Bodensteiner KJ, Wiltbank MC, Bergfelt DR and Ginther OJ (1996b) Alterations in follicular estradiol and gonadotropin receptors during development of bovine antral follicles Theriogenology 45 499-512

Ginther OJ (1995) Ultrasonic Imaging and Animal Reproduction: Horses p 85 Equiservices Publishing, Cross Plains, WI

Ginther OJ, Knopf L and Kastelic JP (1989) Temporal associations among ovarian events in cattle during oestrous cycles with two and three follicular waves Journal of Reproduction and Fertility 87 223-230

Ginther OJ, Wiltbank MC, Fricke PM, Gibbons JR and Kot K (1996) Minireview: selection of the dominant follicle in cattle Biology of Reproduction $\mathbf{5 5}$ 1187-1194

Guilbault LA, Rouillier P, Matton P, Glencross RG, Beard AJ and Knight PG (1993) Relationships between the level of atresia and inhibin contents ( $\alpha$ subunit and $\alpha-\beta$ dimer) in morphologically dominant follicles during their growing and regressing phases of development in cattle Biology of Reproduction 48 268-276 
Ireland JJ, Fogwell RL, Oxender WD, Ames K and Cowley JL (1984) Production of estradiol by each ovary during the estrous cycle of cows Journal of Animal Science 59 764-771

Kaneko H, Terada T, Taya K, Watanabe G, Sasamoto S, Hasegawa Y and Igarashi M (1991) Ovarian follicular dynamics and concentrations of oestradiol-17 $\beta$, progesterone, luteinizing hormone and follicle stimulating hormone during the periovulatory phase of the oestrous cycle in the cow Reproduction and Fertility Development 3 529-535

Ko JCH, Kastelic JP, Del Campo MR and Ginther OJ (I991) Effects of a dominant follicle on ovarian follicular dynamics during the oestrous cycle in heifers Journal of Reproduction and Fertility $91511-519$

Kot K, Gibbons JR and Ginther OJ (1995) A technique for intrafollicular injection in cattle: effects of hCG Theriogenology 44 41-50

Martin TL, Fogwell RL and Ireland JJ (1991) Concentrations of inhibins and steroids in follicular fluid during development of dominant follicles in heifers Biology of Reproduction $44693-700$
Rasmussen FE, Wiltbank MC, Christensen JO and Grumer RR (1996) Effects of fenprostalene and estradiol-17 $\beta$ benzoate on parturition and retained placenta in dairy cows and heifers Journal of Dairy Science 79 227-2.34

Rhodes FM, Fitzpatrick LA, Entwistle KW and Kinder JE (1995) Hormone concentrations in the caudal vena cava during the first ovarian follicular wave of the oestrous cycle in heifers Journal of Reproduction and Fertility 104 33-39

Sunderland SJ, Knight PG, Boland MP, Roche JF and Ireland JJ (1996) Alterations in intrafollicular levels of different molecular mass forms of inhibin during development of follicular- and luteal-phase dominant follicles in heifers Biology of Reproduction 54 453-462

Xu Z, Garverick HA, Smith GW, Smith MF, Hamilton SA and Youngquist RS (1995) Expression of follicle-stimulating hormone and luteinizing hormone receptor messenger ribonucleic acids in bovine follicles during the first follicular wave Biology of Reproduction $53951-957$ 